\title{
Analysis and Predictability of Dry Spell Lengths Observed in Synoptic Stations of Benin Republic (West Africa)
}

\author{
Médard Noukpo Agbazo1,2 (), Joseph Adébiyi Adéchinan³, Gabin Koto N’gobi², Joseph Bessou ${ }^{4}$ \\ ${ }^{1}$ International Chair in Mathematical Physics and Applications (ICMPA-UNESCO Chair), Université d'Abomey-Calavi, \\ Abomey-Calavi, Bénin \\ ${ }^{2}$ Laboratoire de Physique du Rayonnement (LPR), Université d'Abomey-Calavi, Abomey-Calavi, Bénin \\ ${ }^{3}$ Département de Physique, Faculté des Sciences et Techniques, Université Nationale des Sciences, Technologies, \\ Ingénierie et Mathématiques (UNSTIM), Abomey, Bénin \\ ${ }^{4}$ Agence Nationale de la Météorologie du Bénin (METEO BENIN), Cotonou, Bénin \\ Email: agbmednou@gmail.com
}

How to cite this paper: Agbazo, M. N., Adéchinan, J. A., N’gobi, G. K., \& Bessou, J. (2021). Analysis and Predictability of Dry Spell Lengths Observed in Synoptic Stations of Benin Republic (West Africa). American Journal of Climate Change, 10, 597-618. https://doi.org/10.4236/ajcc.2021.104030

Received: October 2, 2021

Accepted: December 28, 2021

Published: December 31, 2021

Copyright (C) 2021 by author(s) and Scientific Research Publishing Inc. This work is licensed under the Creative Commons Attribution-NonCommercial International License (CC BY-NC 4.0). http://creativecommons.org/licenses/by-nc/4.0/

\begin{abstract}
The complex behavior and predictability of the Dry Spell Lengths (DSL) series obtained in Benin synoptic stations, from 1951 to 2010 are analyzed in this paper using a fractal approach. The synoptic stations are located in Cotonou, Bohicon, Save (subequatorial climate), and Parakou, Natitingou, Kandi (Sudanian climate). The DSLs are computed by considering four thresholds level, $\mathrm{R} 0=\{1.0,1.5,2.0$ and 5.0$\} \mathrm{mm} /$ day. The fractal trace is estimated for dry spell density by the mean of the "Dry Spell Spell" (DSS) n-index. The rescaled range method is used to determine the predictability of DSL. By analyzing the DSS, results show that low DSS n-index values $(\mathrm{n}$-index $<0.4)$ are more favored in the northern part of Benin than in the southern region, whereas, high values of DSS n-index ( $n$-index $>0.4$ ) occur preferentially in the southern part. Therefore, during 1951-2010, the Sudanian region presents frequent wet spells, alternated with short dry spells than in the subequatorial one. However, a high degree of long dry spell persistence, followed by short dry events is observed in the subequatorial region than in the Sudanian one. The longest DSL is observed in the subequatorial region, especially in Cotonou. Except for the Kandi station, the DSLs series obtained at synoptic stations are characterized by persistence. Therefore, autoregressive processes could be applied to the DSL series. Generally, the physical process governing dry spells observed at Save, Natitingou, and Bohicon are consistently predictable than the process governing the stations of the Cotonou and Parakou. However, at Kandi station, the DSL process approximates the usual Brownian motion, and it is, therefore, unpredictable or difficult to predict.
\end{abstract}




\section{Keywords}

Hurst Exponent, N-Index, DSL, Predictability, Complex Behavior, Benin

\section{Introduction}

In West Africa, rainfed agriculture is $90 \%$ of the cases responsible for food production, and $80 \%$ of the population in West Africarelieson it for providing its livings (Rockstrom, 2000). However, rainfed agriculture depends highly on the variability of the West African monsoon system, which activities determine the rain regime in the region (FAO, 2016). Rainfed agriculture is sensitive both, to the length and the occurrence of wet and dry spells during the rainy season (Gornall et al., 2010; Froidurot \& Diedhiou, 2017). Thus, the understanding of the variability of wet and dry spells could be used for forecasting a particular crop growth cycle or the variety of crops to sow in a given location of West Africa (Sivakumar, 1992). Dry and wet spells effects have a direct impact on the economy of the countries because they affect, not only agriculture but also the related sectors such as fisheries, health, hydroelectricity (Jayawardene et al., 2005; Mathugama \& Peiris, 2011). For instance, wet and dry spells affect water quality in a drainage basin, which in turn may have health implications for society (Whitworth et al., 2012). Longer dry spells also can interrupt generating electricity in hydroelectric power systems (Jayawardene et al., 2005). In this regard, an understanding of wet and dry spell lengths is crucial for water resources management, for the best planning, and designing applications in agriculture and the environment (Mathugama \& Peiris, 2011; Froidurot \& Diedhiou, 2017). The Dry spell lengths are defined as the number of consecutive days with daily rain amounts lower than a certain chosen threshold. It represents a valuable magnitude to analyze several aspects of drought episodes (Lana et al., 2015). The accurate analysis of dry spell length is relevant for a better understanding of any pluviometric regime (Lana et al., 2008a). It is argued from literature (e.g., Lana et al., 2006, 2008a, 2008b) that the studies of DSLs series could help to improve knowledge of time trends and physical mechanisms governing drought sequences. Several studies have been conducted worldwide to explore the variability of wet and dry spell characteristics. In West Africa, these characteristics have been analyzed focusing on two aspects. The first one is related to the spatial distribution and temporal trend in the wet or dry spells, one can cite: (Sivakumar, 1992; Sanogo et al., 2015; Froidurot \& Diedhiou, 2017; Girma et al., 2020). The second aspect focuses on the curve fitting of probability distribution in wet or dry spells (Ezeh et al., 2016; Salack et al., 2016). Generally, the probabilistic behavior of dry periods' characteristics is determined analytically by assuming a given stochastic structure. The stochastic models used to study dry spells are subdivided into two different groups: the first group mainly refers to the non-homogeneous Poisson model (driven data models), while the second can be represented by Markov 
processes (physically-based models) (Sirangelo et al., 2019; Manikandan et al., 2017; Reddy et al., 2008). The Markov chains probabilistic model is widely used for the analysis of dry and wet spells in different parts of the world for example, in East Africa one can cite studies of: Matarira \& Jury, 1992; Biamah et al., 2005; Sharma, 1996; Bekele, 2001; Barron et al., 2003; Seleshi \& Camberlin, 2006; Fischer et al., 2013; Admasu et al., 2014. In West Africa, the works of Ezeh et al., 2016; Salack et al., 2016; Afouda et al., 2002; Afouda, 1988, 1989, 1990; Afouda \& Adisso, 1997; Le Barbé \& Lebel, 1997 are the most dominant one.

It's argued by (Cahill, 2003; Hui et al., 2005; Muller, 2006) that the first-order Markov chains have a relatively short memory that may limit the model's ability to reproduce adequately long dry and/or wet spells, as well as inter-annual variability. According to Wilks, 1999 and Hayhoe, 2000, higher-order Markov chains, often improve these inadequacies; however, they require an estimation of more parameters thereby placing stricter demands on the amount of input data. Furthermore, the estimation of more parameters introduces uncertainties in the methods or models using these parameters. An alternative to the Markov chains process is to use the wet-dry spell model. The problem is that alternation between dry and wet events presents self-similarity, which is the key characteristic of fractal objects (Martínez et al., 2007; Feng et al., 2015; Dayeen \& Hassan, 2016; Monjo, 2016; Lucena et al., 2018). In this context, the Fractal approach can be an efficient alternative to explore the variability of wet and dry spell characteristics, mainly to study their complexity and predictability (Lana et al., 2010; Lana et al., 2015; Monjo, 2016).

Fractal concepts are reliable tools often used with efficient results to characterize the physical laws governing the complex natural processes taking place in precipitations time series and their predictability (Lana et al., 2010; Lovejoy \& Mandelbrot, 1985; Hubert et al., 1993; Sivakumar et al., 2001; Martınez et al., 2007). However, in West Africa, especially in the Benin Republic, a country challenging agriculture, hydroelectricity, and health sector, the complex behavior, and predictability of DSL series related to fractal theory has never been investigated yet. That is why our study aims to introduce, for the first time, the analysis of the complex behavior of dry spells lengths and quantify the predictability of these dry spell regimes in the fractal framework in the Benin Republic. The content of the paper is organized as follows: (i) collected data and the methodology are presented in Section 2. Section 3 presents the results and discussions. Conclusions are summarized in the final section.

\section{Materials and Methods}

\subsection{Study Area}

The area of study covers the Benin Republic synoptic stations (Kandi, Natitingou, Parakou, Save, Bohicon, and Cotonou) which geographical locations are indicated in Figure 1. The country is located in West Africa between $6^{\circ} 25^{\prime}$ and 


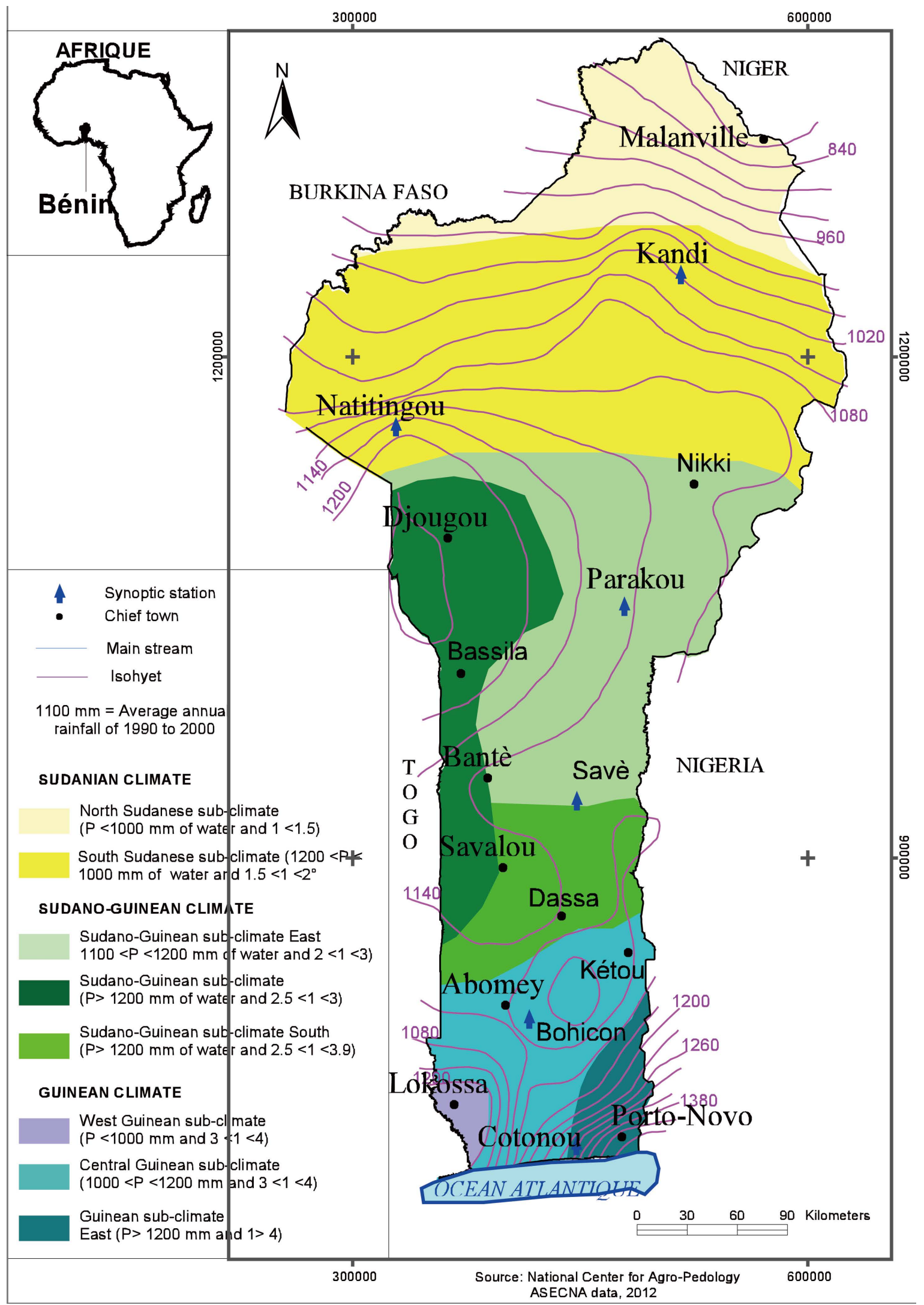

Figure 1. Hydrometeorological map of Benin republic showing the locations of synoptic stations', the climate regimes, and precipitations isohyets. 
$12^{\circ} 30^{\prime}$ North latitude and $0^{\circ} 45^{\prime}$ and $4^{\circ}$ East longitude. Benin is characterized by three main climatic zones: the Sudanianclimate in the northern part where Kandi, Natitingou, and Parakou stations are located. Whereas, Save, Bohicon, and Cotonou are located in the Subequatorial climate. Sometimes, Save station is considered as located in the transition area between the Sudanian and the subequatorial one. According to Boko (1988), the Sudanian climate zone is characterized by the succession in the year of a single dry season (November to March) and a rainy season with maximum rainfall in August September. Whereas, the Subequatorial climate is characterized by a bimodal rainfall regime. There are four more or less marked seasons: two rainy seasons (March to July and September to November) and two dry seasons (July to September and November to March). The rainfall maxima usually take place in June for the long rainy season and in October for the short rainy season. The transition zone between the Sudanianclimate and the subequatorial climate is located from the latitude of Bohicon to the latitude of Tchaourou (Near Parakou station).

\subsection{Data Analysis}

Daily rainfall data used in this study are collected from the six synoptic stations of Benin and were provided by "Météo-Bénin", the Benin meteorology service in charge of climatic data. In the present study, only the rainfall data recorded during the rainy season over the period from 1951 to 2010 are considered. The descriptive statistics of the precipitation time series collected during the study period are presented in Table 1 . The highest maximum value of precipitation during the study period is observed at the Cotonou station. In contrast, the lowest value is noticed at Bohicon station. The skewness and kurtosis parameters of the precipitation time series present information about differences in their statistical distributions. Precipitation reveals a positive skewness at all the synoptic stations which indicates that the distributions are right-tailed. The lowest skewness and kurtosis values are observed at Natitingou, informing that the precipitation's distribution at this station has a more rounded peak and thinner tails, compared to the other stations. However, the highest skewness and kurtosis values are observed at Cotonou, indicating strongly right-tailed distributions with sharp peaks and fat tails. For more detail in the study area, the reader can see Agbazo et al. $(2019,2021)$.

Table 1. Statistical description of the whole sixty-year daily meteorological time series from Benin's synoptic stations.

\begin{tabular}{ccccc}
\hline Synoptic stations & Min & Max & Skewness & Kurtosis \\
\hline Cotonou & 0 & 194.2 & 4.68 & 33.15 \\
Bohicon & 0 & 128.5 & 4.00 & 23.60 \\
Save & 0 & 184.2 & 4.31 & 30.60 \\
Parakou & 0 & 176 & 4.00 & 27.17 \\
Natitingou & 0 & 149.7 & 3.20 & 17.487 \\
Kandi & 0 & 157.8 & 3.69 & 22.62 \\
\hline
\end{tabular}




\subsection{Background for Dry Spells Length}

A dry spell length is defined as a period of consecutive days with rainfall below a given threshold. The thresholds value, commonly used to define a dry spell length (DSL) in various parts of the world are 0.1, 0.85, 1.0, 1.5, 2, 5.0 and 10.0 mm/day (Kutiel \& Maheras, 1992; Harrington \& Flannignan, 1993; Perzyna, 1994; Anagnostopoulou et al., 2003; Serra et al., 2006, 2013, 2014; Groisman \& Knight, 2008; Zolina et al., 2013). In Africa, 0.8 or $1 \mathrm{~mm}$ /day had been used (Seleshi \& Camberlin, 2006; Froidurot \& Diedhiou, 2017). Sometimes, these thresholds are considered insufficient for crops use (Sivakumar, 1992; Froidurot \& Diedhiou, 2017). Rainfall amount less than $1.0 \mathrm{~mm}$ is supposed to evaporate directly before any use (Chaudry \& Sheikh, 2001; Douguedroit, 1987; Lázaro et al., 2001; Epifani et al., 2004). In the current study, DSLs series are computed by considering four thresholds level, $\mathrm{R} 0=\{1.0,1.5,2.0$, and 5.0$\} \mathrm{mm} /$ day. As a long dry spell has strong influences on agriculture and drought, DSLs are generally divided into short and long dry spells by various authors (e.g., Sivakumar, 1992; Bonsal \& Lawford, 1999; Huth et al., 2000; Gong et al., 2005). The short dry spells are defined as those events with alength shorter than 10 days while the long dry spells refer to the others (Gong et al., 2005). In this paper, the same division is made on the DSLs time series. Moreover, the DSLs series are computed in each station during its rainy season according to its corresponding climatic zone. Computation of dry spells is done during rainy seasons. The MATLAB software codes are rewritten and used to achieve the study calculations.

\subsection{Dry Spell N-Index Calculation}

The DSL structure is analyzed with the use of self-similarity features obtained from the DSS n-index, which is developed by Monjo et al. (2019). According to Monjo et al. (2019) DSS n-index method can be briefly described as follows:

Let $\left\{D_{t} \mid t=1,2, \cdots, N\right\}$ be a time series of consecutive dry spells duration. Different independent events ("spells of spells") are built around the dry value $\left(D_{0}=\right.$ 1) and each separated event is referred to as a "dry spell spell". The maximum accumulated dry spell duration $\left(P_{i}\right)$ of a DSS event is defined as:

$$
P_{i}=\max \left\{\sum_{j=k}^{k+i-1} D_{j}\right\}_{k=1}^{N-i+1}
$$

where $i$ is the number of accumulated events, and $N$ is the total of considered events.

For each DSS event, the maximum average duration $Y_{i}$ at $i$-step is:

$$
Y_{i}=\frac{P_{i}}{i}
$$

Therefore, the maximum average duration satisfies a scaling relationship concerning this event number:

$$
\frac{Y_{i}}{Y_{1}}=\left(\frac{1}{i}\right)^{n}
$$


$Y_{1}$ is the maximum expected dry length per year and $n$ is the DSS $n$-index. Moreover, $d \leq n \leq 1$, where, $d$ is the fractal dimension of the spells considered (Monjo, 2016).

From, Equations (2) and (3), $P_{i}$ can be deduced as:

$$
P_{i}=Y_{i} i^{(1-n)}
$$

For each DSLs series, the parameters $Y_{1}$ and DSS n-index is fitted for each DSS and averaged at each synoptic station.

Information on the structure of the drought lacunarity is provided by the DSS n-index, specifically, it measures the probability of irregularity (if $n \sim 1$ ) or regularity (if $n \sim 0$ ). Dry spells are considered regular values when similar dry spell lengths are usually consecutive. In contrast, generally, long dry spells are followed by much shorter dry sequences in the irregular values cases. It is important to keep in mind that a high degree of irregularity is correlated with the longest dry spells. As in Monjo et al. (2019), DSS n-index values are considered as: 1) lower if DSS n-index is lower than $0.3 ; 2$ ) medium when DSS $n$-index is between 0.3 and 0.4 , and 3) higher when DSS n-index is greater than 0.4.

\subsection{Rescaled Analysis}

The predictability of complex dynamic systems such as the DSL series is quantified by interpreting the meaning of the Hurst exponent (H) (Feder, 1988; Goltz, 1997; Lana et al., 2010). Indeed, 1) the DSL series will present a clear sign of randomness when its Hurst exponent value is equal to $0.5,2$ ) the DSL series will present persistence (time trends on a previous DSL series contribute to DSL prediction) if Hurst exponent value is well above $0.5,3$ ) in a contrast, the DSL series will present anti-persistence (an average of all previous DSL values contributes to DSL prediction), when Hurst exponent value is well below 0.5 (Lana et al., 2010). To calculate the Hurst exponent, numerous approaches are proposed in the scientific literature (Peng et al., 1994; Peters, 1994; Taqqu et al., 1995; Kendziorski, 1999). Among these, the method of rescaled-range (R/S) analysis is used in the present study (Peters, 1994; Mandelbrot, 1985; Feder, 1988). The Rescaled-range $(\mathrm{R} / \mathrm{S})$ analysis is chosen because it is the most efficient method used in literature.

The description of the one-dimensional R/S analysis (Hurst, 1951; Lana et al., 2010; Tatli, 2015) is shown below:

Let $\left\{y_{t} \mid t=1,2, \cdots, N\right\}$ be an original DSL series. The R/S statistics areestimated by computing the subsets of DSL series mean $\bar{y}_{\tau}=\frac{1}{\tau} \sum_{k=1}^{\tau} y_{k}$, also $R_{\tau}$ and $S_{\tau}$ are given respectively by (5) and (6):

$$
\begin{gathered}
R_{\tau}=\left[\max _{1 \leq i \leq \tau} \sum_{k=1}^{i}\left(y_{k}-\bar{y}_{\tau}\right)-\min _{1 \leq i \leq \tau} \sum_{k=1}^{i}\left(y_{k}-\bar{y}_{\tau}\right)\right] \\
S_{\tau}=\left[\frac{1}{\tau} \sum_{k=1}^{\tau}\left(y_{k}-\bar{y}_{\tau}\right)^{2}\right]^{1 / 2}
\end{gathered}
$$

where, $1 \leq \tau \leq N, S_{\tau}$ is the standard deviation. If the fractal behavior exists, 
the rescaled range $(R / S)_{\tau}=R_{\tau} / S_{\tau}$ follows a power-law relationship:

$$
(R / S)_{\tau}=a \tau^{H}
$$

$H$ is the Hurst exponent and $a$ is a constant and Hurst exponent is the slope obtained by plotting $\log (R / S)_{\tau}$ versus $\log (\tau)$ as:

$$
\log (R / S)_{\tau}=\log a+H \cdot \log (\tau)
$$

The rescaled analysis is performed on DSLs series obtained by considering the four thresholds level $R_{0}=\{1.0,1.5,2.0$, and 5.0$\} \mathrm{mm} /$ day. The predictability index (PI) and the Hurst exponent are related as (Voss, 1985; Rangarajan \& Sant, 1997, 2004; Mittall \& Bhardwaj, 2011):

$$
\mathrm{PI}=2|0.5-H|
$$

The corresponding process is unpredictable when PI is closed to zero. In contrast, the studied process is very predictable if PI is closed to one (Mittall \& Bhardwaj, 2011).

\section{Results and Discussion}

Figure 2 compares the frequency of occurrence ( $\mathrm{FoO}$ ) of the DSS n-index at each synoptic station. The results show that: 1) when considering the thresholds level, $R_{0}=\{1.0,1.5,2.0$ and 5.0 $\mathrm{mm} /$ day, the FoO of lower DSS n-index, which values are lower than 0.3 from the synoptic stations located in Sudanian climate (Kandi, Natitingou and Parakou) are systematically higher than those obtained at the station located in Subequatorial climate (Save, Bohicon and Cotonou). This result indicates that the lower DSS n-index is more favored in the northern part (in the Sudanian area) of Benin than in the southern part (in Subequatorial). Moreover, for $R_{0}=\{1.0,1.5,2.0\} \mathrm{mm} /$ day, the highest FoO of lower DSS $\mathrm{n}$-index is obtained at Natitingou station and the lowest one is obtained at Save. However, when $R_{0}=\{5.0\} \mathrm{mm} /$ day, the highest FoO of lower DSS n-index is obtained at Kandi station and the lowest is obtained at Bohicon station. These findings imply that the Northern Benin (Sudanian climate) is more characterized by high degree of persistence of very short dry spells, alternating with very frequent wetdays than in the southern part. These results are in agreement with the findings of Monjo et al. (2019), who have shown that low values of DSS $\mathrm{n}$-index are generally found in rainforest zones, which climate is similar to those of Sudanian one. 2) Whatever, the thresholds level considered, excepted at Cotonou station, the FoO of medium DSS n-index (DSS n-index is between 0.3 and 0.4) obtained in Subequatorial climate are systematically greater than those obtained in lower DSS n-index case. However, the opposite findings are obtained in Sudanian climate. Overall stations and thresholds level considered, the lowest FoO of medium DSS n-index is obtained at Cotonou. 3) It is noted that when the thresholds level, $R_{0}=\{1.0,1.5,2.0$ and 5.0$\} \mathrm{mm} /$ day are considered, the FoO of higher DSS n-index (DSS n-indexgreater than 0.4) obtained at the station located in Subequatorial climate (Savè, Bohicon and Cotonou) are systematically 

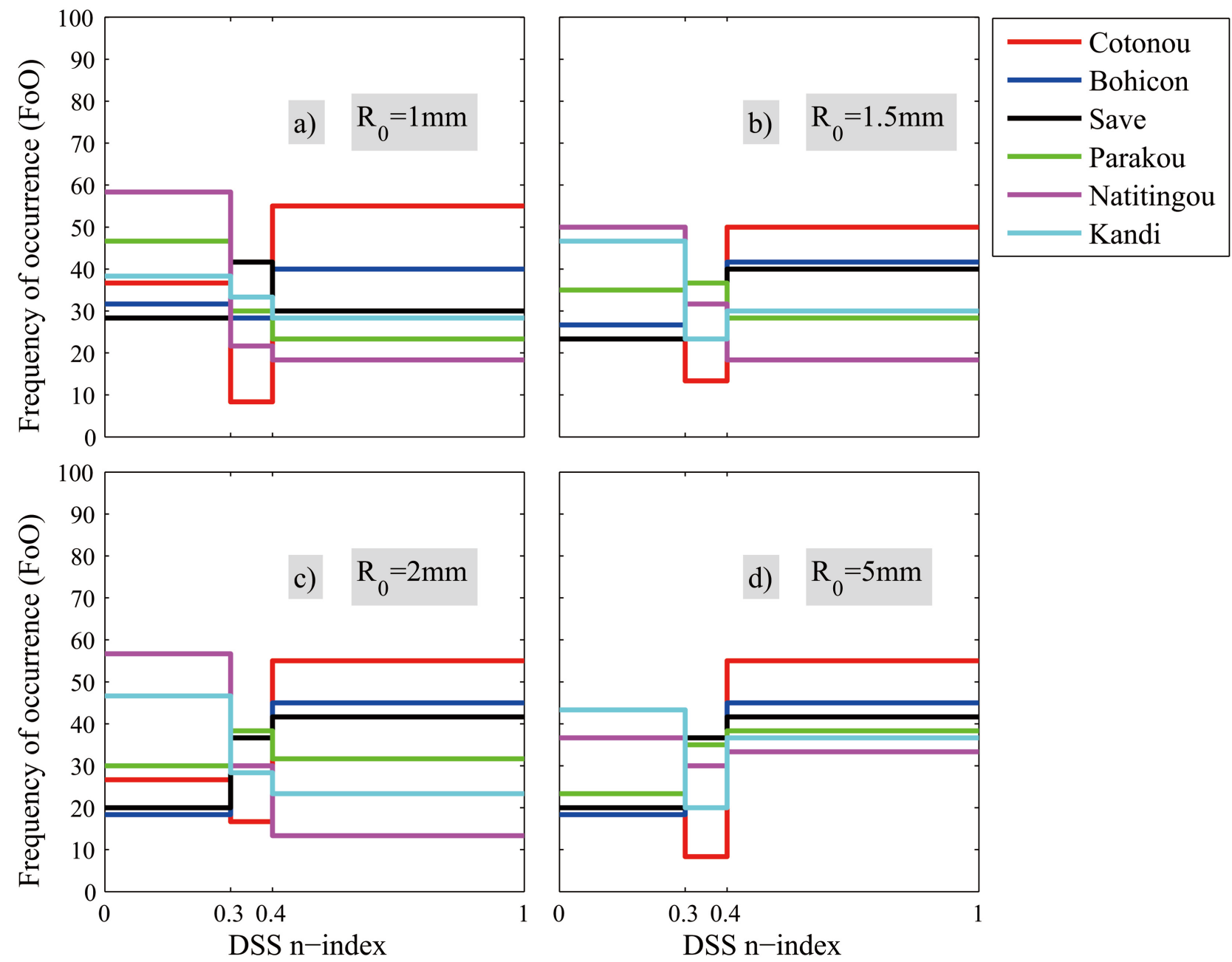

Figure 2. Histograms of the frequency of occurrence (FoO) of DSS n-index per bins (size 0.2) of DSS n-index values obtained for DSLs series with different thresholds level, $R_{0}$, of $1.0 \mathrm{~mm} /$ day (a), $1.5 \mathrm{~mm} /$ day (b), $2.0 \mathrm{~mm} /$ day (c) and $5.0 \mathrm{~mm} /$ day (d).

higher than those obtained at (Kandi, Natitingou and Parakou) synoptic stations located in Sudanian climate. These findings indicate that the higher DSS n-index occurs preferentially in the southern part. Furthermore, the highest and lowest values are obtained respectively at Cotonou and Natitingou station. These results mean that the Subequatorial climate is characterized by the highest values of DSS n-index, which involve a long dry spell followed by shorter dry events. These findings are consistent with those of Monjo et al. (2019), who argued that the tropical and subtropical regions are characterized by high values of the index (n-index $>0.4$ ). The findings at Cotonou could be explained by the fact that Cotonou is very closer to the Atlantic Ocean (a.s.l $3.5 \mathrm{~m}$ ), which strongly influences the structure of its precipitation's regime. Whereas those obtained at Natitingou station are not surprising because the region of Natitingou is known as the most watered area of Benin. It is also a mountainous area.

Figure 3 presents the same as Figure 2 but for two groups of DSS n-index ( $\mathrm{n}$-index $<0.4$ and $\mathrm{n}$-index $>0.4$ ). The first group is obtained when we combine 

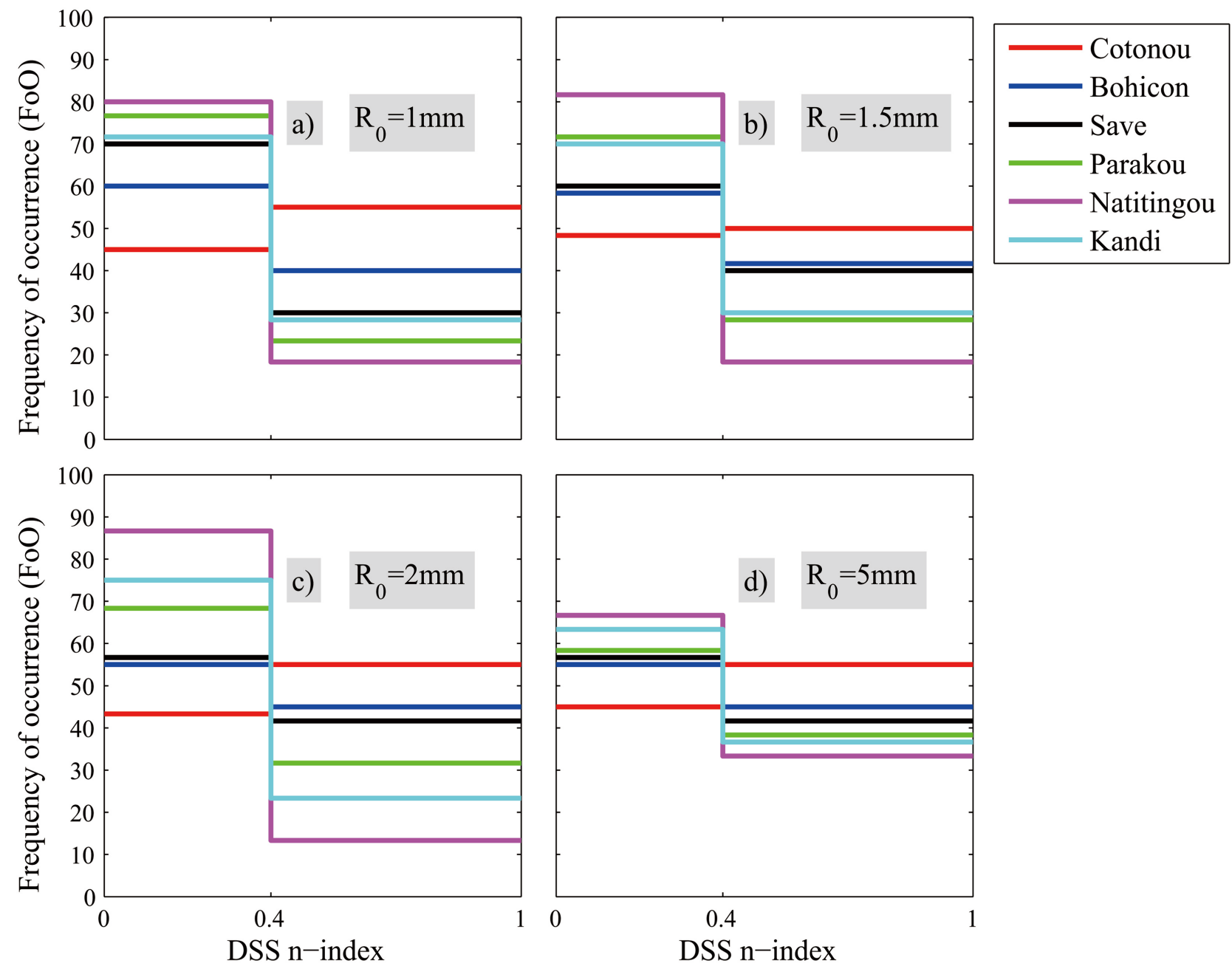

Figure 3. Same as Figure 2 but for two groups of DSS n-index (n-index $<0.4$ and n-index $>0.4$ ).

lower DSS n-index (DSS n-index lower than 0.3) and medium DSS n-index (DSS $\mathrm{n}$-index is between 0.3 and 0.4 ), the second one is the higher DSS $n$-index (DSS $\mathrm{n}$-index greater than 0.4 ).

The results presented in Figure 4 concerned only DSLs series obtained by considering the thresholds level of $1.0 \mathrm{~mm} /$ day. But the result is qualitatively the same for thresholds levels of 1.5 and $2.0 \mathrm{~mm} /$ day. Figure 4 shows the number of values per $2 \mathrm{D}$ bin for the maximum expected dry spell, $Y_{1}$, and DSS n-index, per synoptic station for DSLs series obtained by considering thresholds level of 1.0 $\mathrm{mm} /$ day. The results (Figure 3 and Figure 4) suggest that DSS n-index appears preferentially between 0.0 and 0.4 . Therefore, the predominance of low (DSS $\mathrm{n}$-index $\mathrm{n}<0.3)$, medium (DSS $\mathrm{n}$-index within the interval $(0.3,0.4)$ ) values of the DSS $\mathrm{n}$-index is identified in Benin synoptic stations during the period 1951-2010. Based on the classification made by (Monjo et al., 2019), these results indicate that generally Benin synoptic stations are characterized by frequent wet spells alternating with short dry spells. Moreover, at these stations, the maximum expected dry spell is generally lower than 10 days. Thus, they could have a 


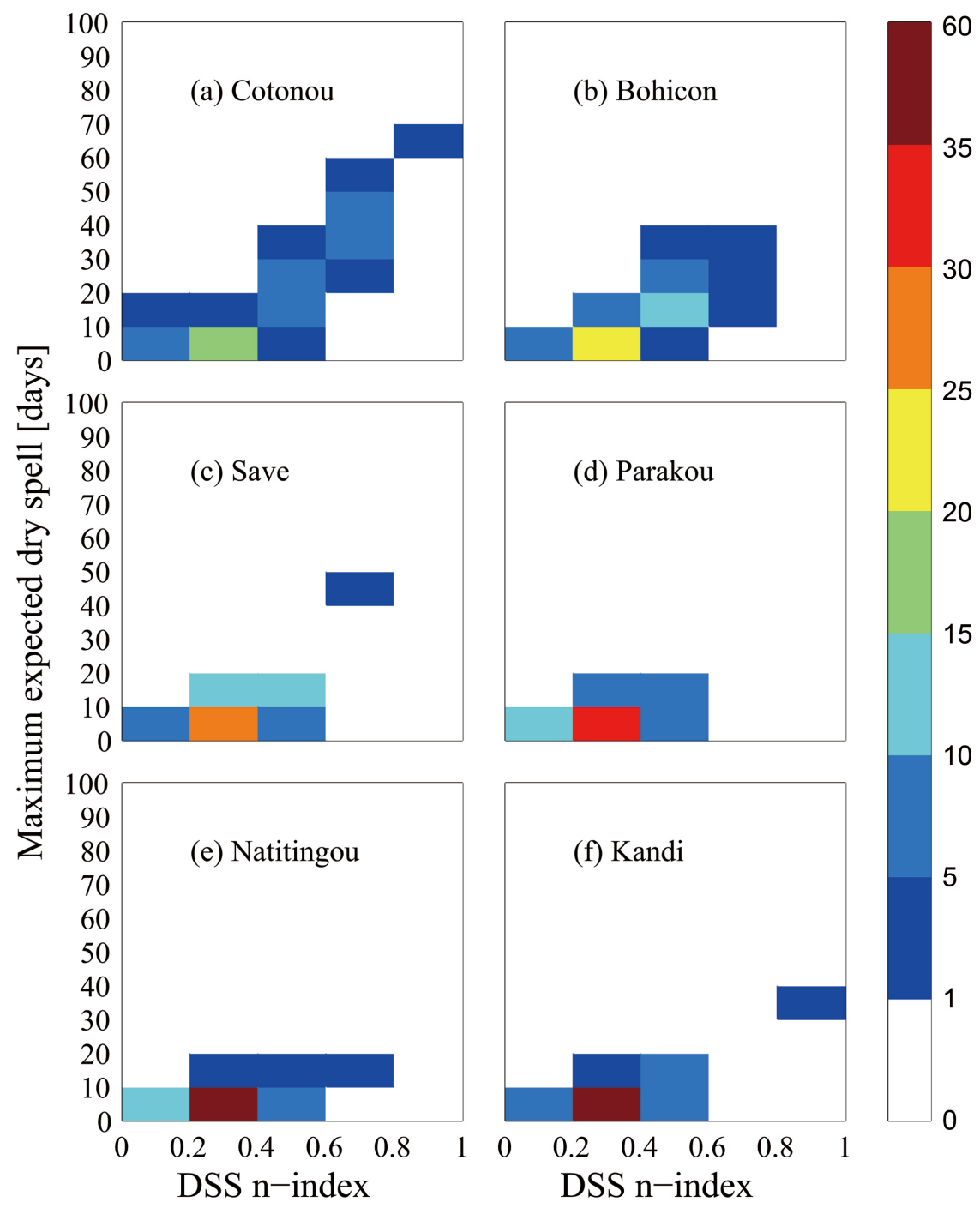

Figure 4. The number of values per two-dimensional bin $(10$ days $\times 0.2)$ of maximum expected dry spell $\left(Y_{1}\right)$ and DSS n-index, per synoptic station for DSLs series obtained by considering thresholds level of $1.0 \mathrm{~mm} /$ day.

low influence on agriculture and drought. From literature, only long dry spells (DSL with length longer than 10 days) have a strong influence on agriculture and drought (Sivakumar, 1992; Bonsal \& Lawford, 1999; Huth et al., 2000; Gong et al., 2005). Despite the predominance of low, medium values of the DSS n-index, it is important to highlight those high values of the DSS n-index associated with longer dry spells are also identified at Cotonou station (subequatorial region). This result reveals the occurrence of very long dry spells alternating with short or long wet events in southern Benin.

Figure 5 and Figure 6 present the averaged values of the maximum expected dry length per year $\left(Y_{1}\right)$ over 1951-2010 and DSS n-index per synoptic station for each DSL series. From Figure 5 and Figure 6, the South-North distribution of averaged values of $Y_{1}$ and DSS n-index shows that whatever the thresholds among the chosen ones, the highest and lowest values of these two parameters 


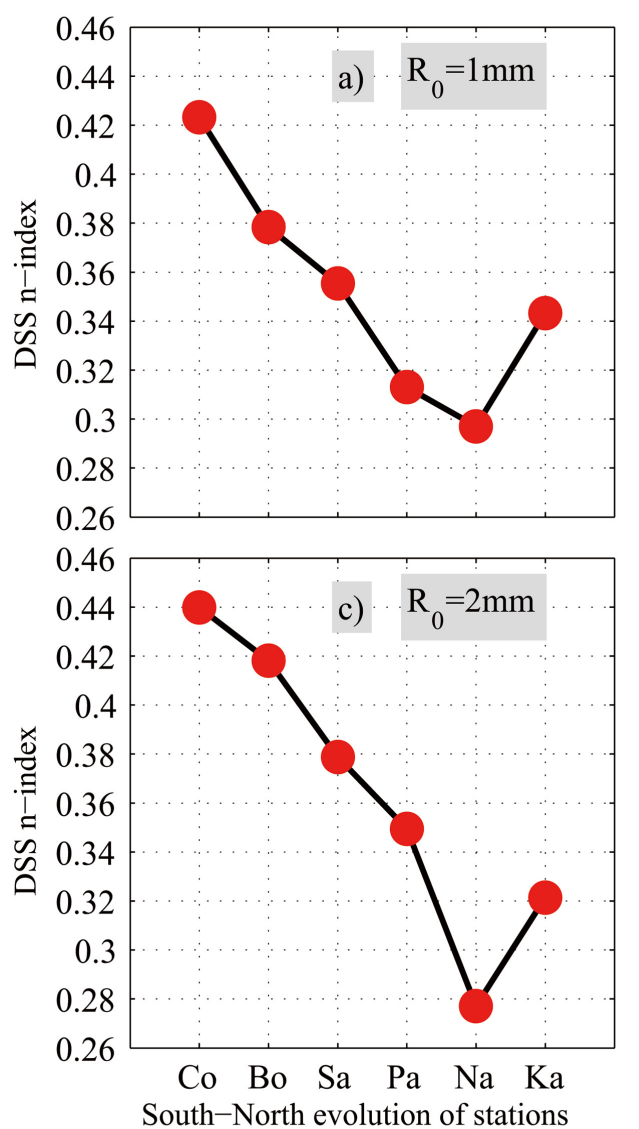

South-North evolution of stations
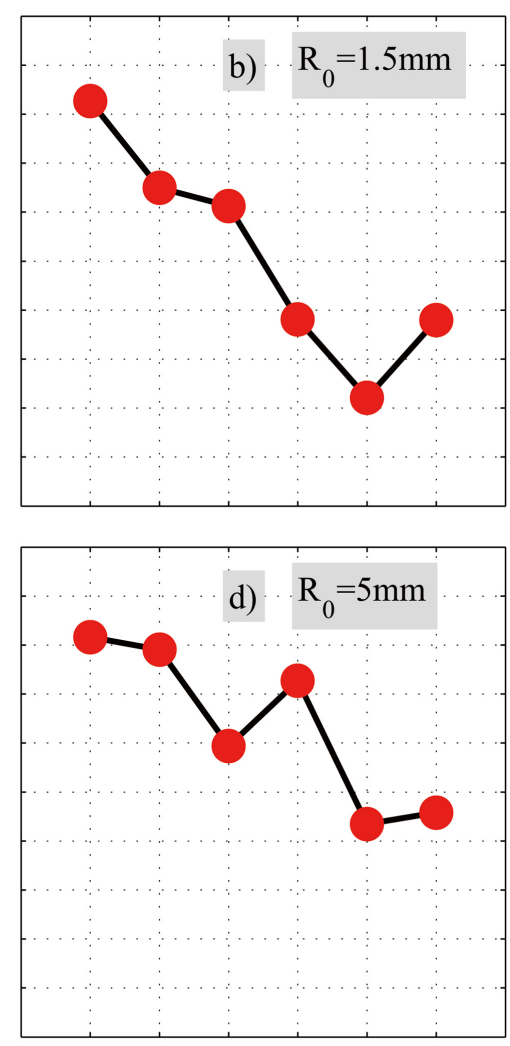

$\mathrm{Co}$ Bo $\mathrm{Sa} \mathrm{Pa} \mathrm{Na} \mathrm{Ka}$ South-North evolution of stations

Figure 5. South-North distribution of the averaged values over 1951-2010 of DSS n-index for DSLs series with different thresholds level, $R_{0}$, of $1.0 \mathrm{~mm} /$ day (a), $1.5 \mathrm{~mm} /$ day (b), 2.0 $\mathrm{mm} /$ day (c) and $5.0 \mathrm{~mm} /$ day (d). Cotonou (Co), Bohicon (Bo), Save (Sa), Parakou (Pa), Natitingou $(\mathrm{Na})$, and Kandi $(\mathrm{Ka})$.

are, respectively, obtained at Cotonou and Natitingou stations. The coincidence of the highest and lowest values of $Y_{1}$ and DSS n-index at the same station is logical because the n-index is strongly correlated with the maximum and the average lengths of dry spells (Monjo et al., 2019). The lowest values of $Y_{1}$ ( $\sim 6$ days) and DSS n-index $(\sim 0.3)$ obtained at Natitingou station indicate that Natitingou is, therefore, more watered, which is not surprising from Benin precipitation regime (Boko, 1988). However, the highest values of $Y_{1}(\sim 19$ days) and DSS $\mathrm{n}$-index ( $\sim$ 0.43) obtained at Cotonou may be due firstly to the influence of the Atlantic Ocean, very closed to Cotonou Synoptic station as we have mentioned above. It could affect Cotonou's rainfall by the usual variation of sea surface temperature or sea humid air circulation around the station. Also, the anthropic effect created by the presence of many industries, and the airport around the measurement site could highly influence the precipitation regime. It appears that, except Kandi station, averaged values of $Y_{1}$ and DSS n-index decrease remarkably with the latitude.

Figure 7 shows the South-North distribution of Hurst exponents throughout the stations for the four thresholds level, $R_{0}=\{1.0,1.5,2.0$, and 5.0$\} \mathrm{mm} /$ day. It 

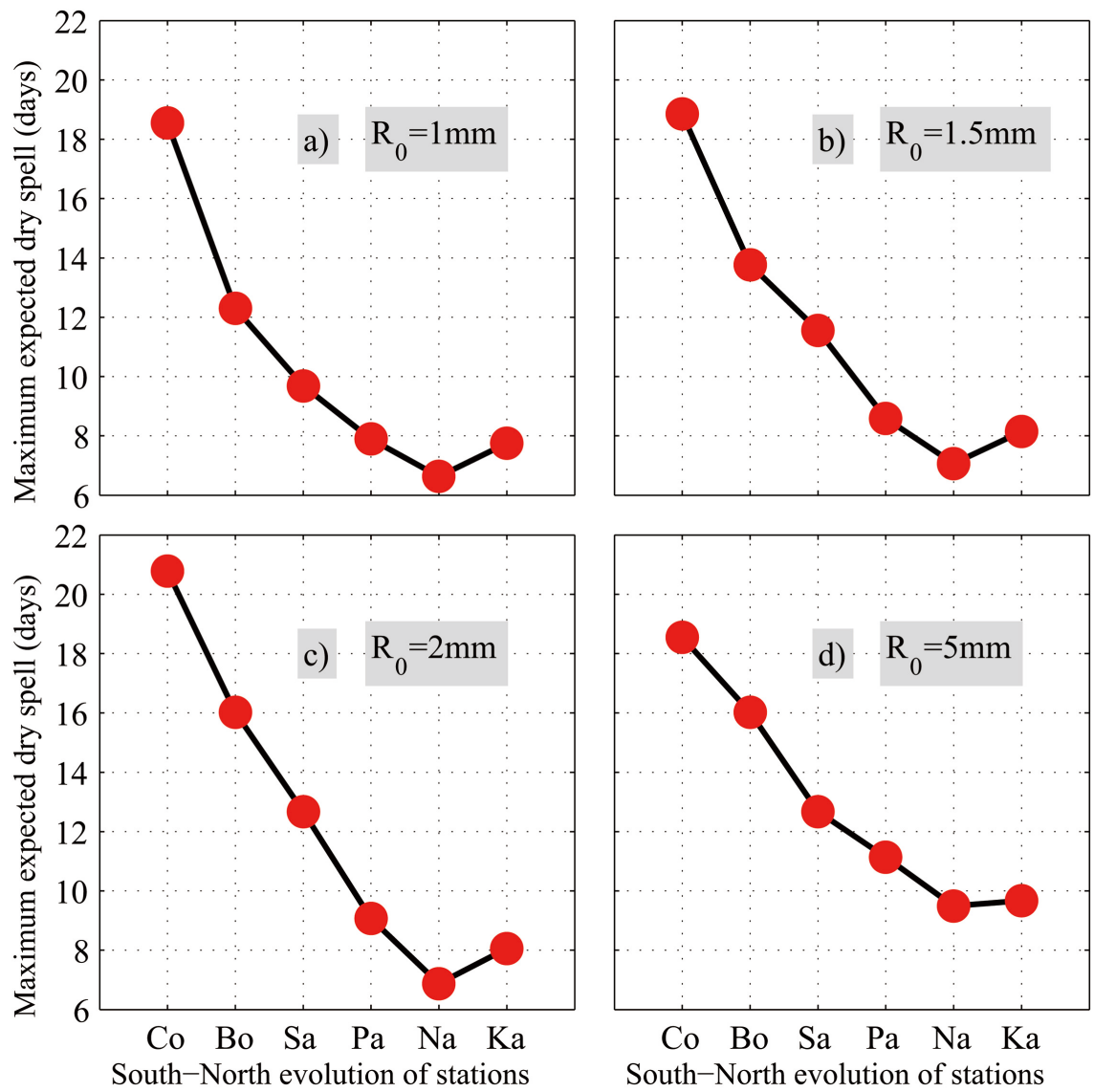

Figure 6. South-North distribution of the averaged values over 1951-2010 of the maximum expected dry length per year $\left(Y_{1}\right)$ for DSLs series with different thresholds levels, $R_{0}$, of $1.0 \mathrm{~mm} /$ day (a), $1.5 \mathrm{~mm} /$ day (b), $2.0 \mathrm{~mm} /$ day (c) and and $5.0 \mathrm{~mm} /$ day (d). Cotonou (Co), Bohicon (Bo), Savè (Sa), Parakou (Pa), Natitingou (Na), and Kandi (Ka).

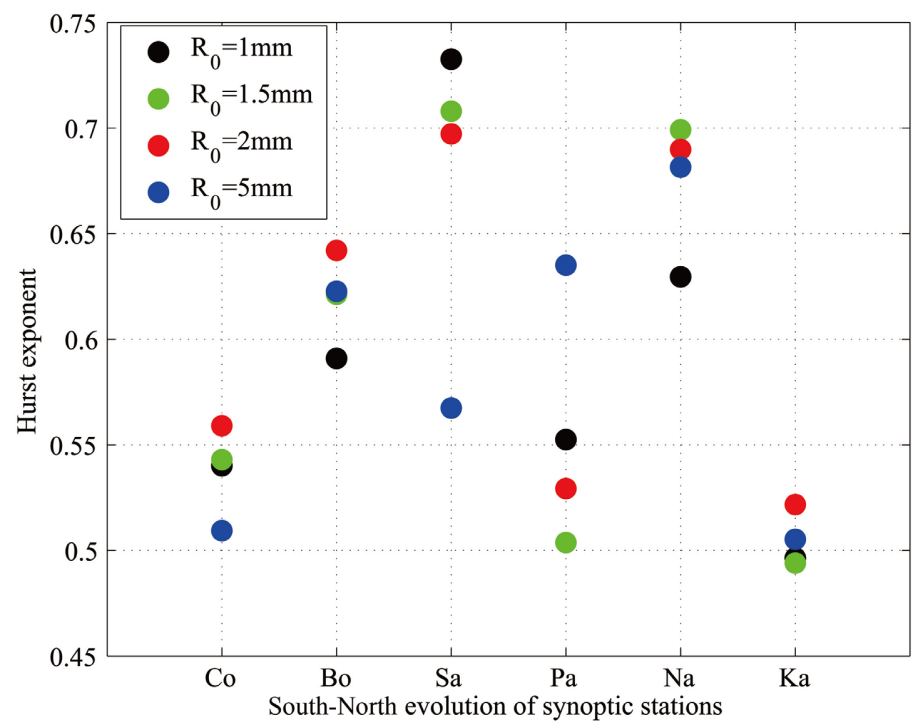

Figure 7. South-North distribution of the Hurst exponent for the four DSLs series with different thresholds levels, $R_{0}$, of 1.0, 1.5, 2.0, and $5.0 \mathrm{~mm} /$ day. Cotonou (Co), Bohicon (Bo), Save (Sa), Parakou (Pa), Natitingou (Na), and Kandi (Ka). 
suggests that the same local rainfall regime frequently generates DSL series with predictive characteristics, varying from lower persistence to stronger persistence, depending on the threshold $R_{0}$. This indicates a sign of complexity in the DSL series from the rainfall regime in Benin. Kandi is the synoptic station where the lower values of $H$ are obtained whatever the thresholds level. Moreover, at this station, Hurst exponents are very close to 0.5 (i.e., the associated fractal dimension could be 1.5) for the four thresholds. This is an evident sign of randomness of the physical process governing dry spells observed at Kandi. The findings could be explained by the fact that Kandi is near the Sahelian desert region where the precipitation regime is strongly influenced by dryer air, often blowing from the Sahara to that region each year. Except for Kandi station, Benin synoptic stations are characterized by Hurst exponents values exceeding 0.5 , especially for 1.0, 2.0, and $5.0 \mathrm{~mm} /$ day, $H$ values are within $0.53-0.73$ interval. Therefore, the DSLs series is characterized by a persistent character in these synoptic stations of Benin. Moreover, the intensity level of the persistence depends on the type of climate and the chosen thresholds level. Thus, time trends on previous DSL series contribute to DSL prediction. In this regard, autoregressive processes could be applied to DSL series, excepted to those obtained at Kandi synoptic station.

Figure 8 presents the latitudinal variation of the Pearson coefficient for Hurst exponent for each of the four thresholds level $R_{0}$. The results show that whatever the thresholds level $R_{0}$, the Hurst exponent is estimated by a Pearson coefficient

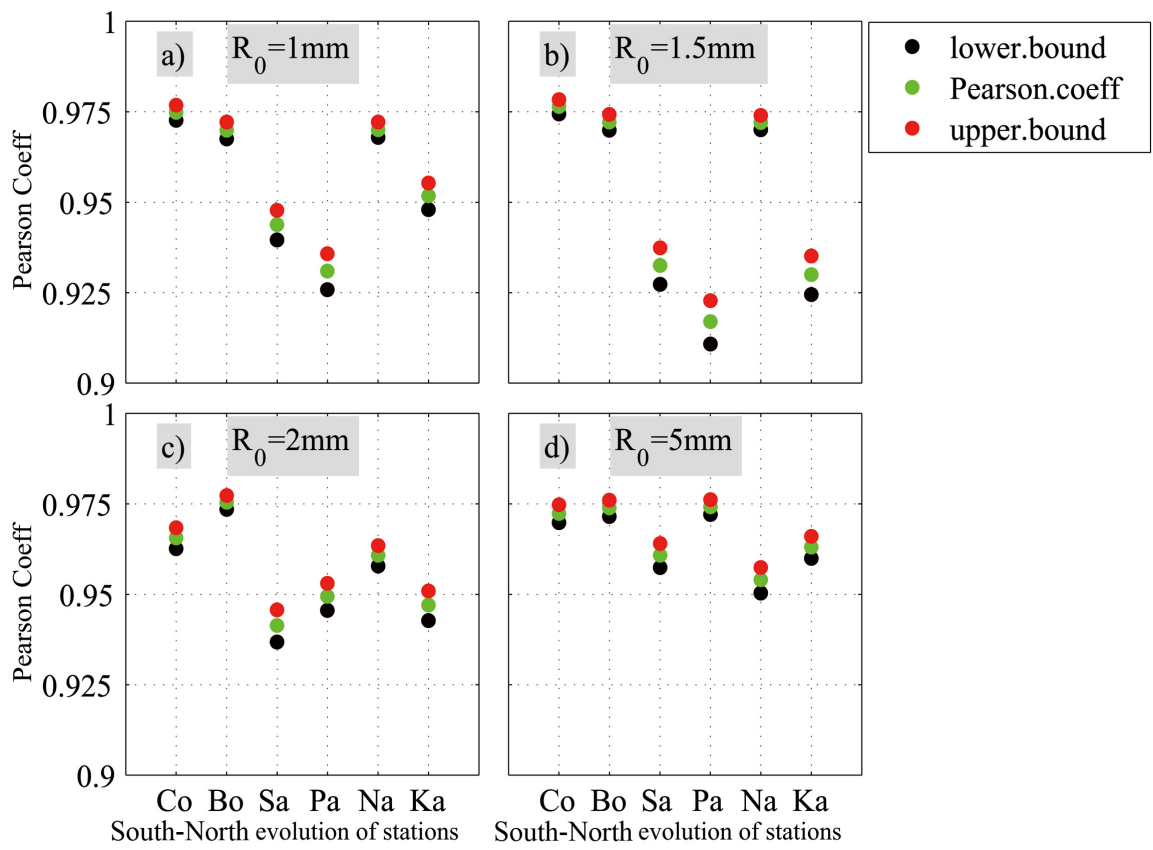

Figure 8. Spatio-temporal variation of the Pearson coefficient for Hurst exponent obtained for the four thresholds level, $R_{\mathscr{b}}$ of $1.0,1.5,2.0$, and $5.0 \mathrm{~mm} /$ day. Red and black represent the upper bound and the lower bound of the $95 \%$ confidence interval. Green represents the Pearson coefficient. Cotonou (Co), Bohicon (Bo), Save (Sa), Parakou (Pa), Natitingou $(\mathrm{Na})$, and Kandi (Ka). 


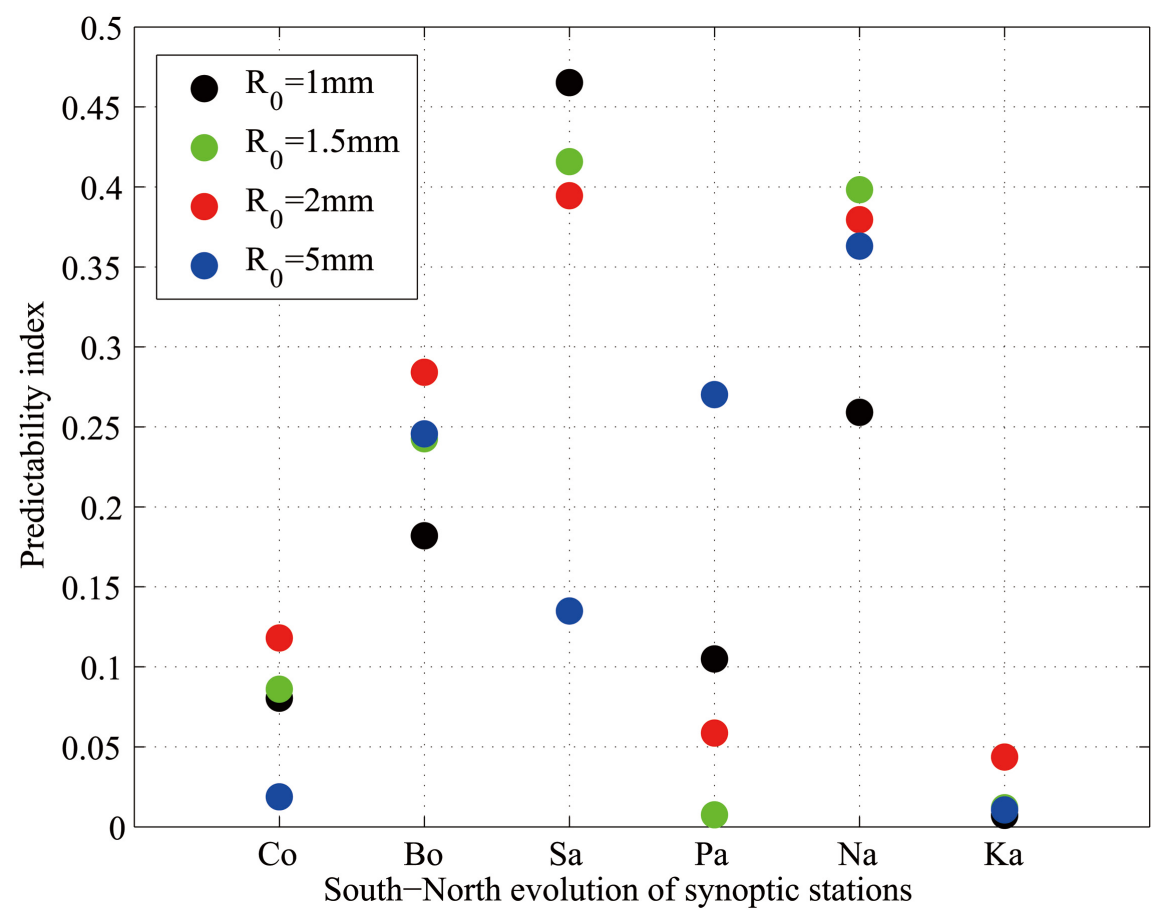

Figure 9. Dry spell length predictability graph for the four thresholds level, $R_{0}$, of 1.0, 1.5, 2.0, and $5.0 \mathrm{~mm} /$ day. Cotonou (Co), Bohicon (Bo), Savè (Sa), Parakou (Pa), Natitingou $(\mathrm{Na})$, and Kandi $(\mathrm{Ka})$.

between 0.90 and 0.97 , indicating the robustness of the linear regression used to fit the log-log representation. The upper and the lower bound of the $95 \%$ confidence interval obtained through Fisher's z-transformation (Wilks, 2006) have the same sign meaning that the computation is statistically significant.

Figure 9 presents the predictability indices (PI) for DSLs series obtained by considering respectively the four thresholds level, R0, of 1.0, 1.5, 2.0, and 5.0 $\mathrm{mm}$ /day. The spatial distribution of the PI values shows large variability of PI across synoptic stations and thresholds level. Therefore, the predictability indices of DSLs depend on the geographical location and the chosen thresholds level used to define a dry spell length (DSL). These results suggest that generally, the physical process governing dry spells observed at Save, Natitingou, and Bohicon are consistently predictable than the process governing dry spell at Cotonou and Parakou DSLs series. However, at Kandi station PI value is generally closer to zero, then the DSL process approximates the usual Brownian motion and is, therefore, unpredictable or difficult to predict, showing the complex behavior and predictability of DSL series in Benin. The patterns extracted by the predictability index give much more insight than the $H$ values obtained above.

\section{Conclusion}

The main objective of this paper is to study the complex behavior and predictability of DSL series obtained in Benin synoptic stations from 1951 to 2010 using the $\mathrm{n}$-index and rescaled range method. DSLs are computed by considering four 
thresholds level, $R_{0}=\{1.0,1.5,2.0$ and 5.0$\} \mathrm{mm} /$ day. The main findings obtained can be summarized as follows:

1) The predominance of low and medium DSS n-index values ( $n$-index $<0.4$ ) is identified in the northern part of Benin, whereas, high values of DSS n-index (n-index $>0.4$ ) occur preferentially in the southern part. Therefore, the occurrence of the short dry spells (lower than 10 days) alternating with longer or shorter wet spells occurs preferentially in northern Benin than in the southern part. However, the occurrence of long dry spells (DSL with a length longer than 10 days) alternating with short or long wet events is more favored in the southern part of Benin.

2) The highest and lowest values of averaged values over 1951-2010 of the maximums expected dry length per year $\left(Y_{1}\right)$ and DSS n-index are obtained respectively, at Cotonou and Natitingou stations. The lowest averaged values of $Y_{1}$ and DSS $\mathrm{n}$-index are respectively $\sim 6$ days and $\sim 0.3$ whereas the highest values are $\sim 19$ days and $\sim 0.43$.

3) It appears that, except Kandi station, averaged values of $Y_{1}$ and DSS n-index decrease remarkably with the latitude.

4) Randomness and persistence are present in the Beninese DSL series. Thus, time trends on previous DSL series contribute to DSL prediction. Therefore, autoregressive processes would apply to the DSL series obtained at the synoptic stations, excepted at Kandi station.

5) The predictability indices (PI) of DSLs depends on the geographical location, and the thresholds level used to define a dry spell length (DSL). The physical process governing dry spells observed at Save, Natitingou, and Bohicon are consistently predictable than that governing Cotonou and Parakou DSLs series. However, at Kandi station PI is generally closed to zero, thus the DSL process approximates the usual Brownian motion and is, therefore, unpredictable or difficult to predict.

Although dry spell processes are a complex dynamic system, they are consistently predictable at some stations and not at others in Benin Republic. Thus, it is possible to develop such predictable strategies for monitoring and managing droughts and dry spell regimes to solve agriculture and hydroelectricity problems related to water resources. The implications of our findings for agricultural production in Benin refer to: 1) the consideration of dryness lacunarity, which provides a better understanding of drought duration and can help to predict DSLs when droughts start and finish; 2) the characterization of the temporal and spatial patterns of drought; 3 ) the study of DSL time series predictability by Hurst exponent, which permits characterizing the persistence, anti-persistence or randomness of DSL.

The present study limitations refer to the study period and to the fact that only the synoptic stations DSL time series are analyzed. It's must be useful to explore drought lacunarity and its predictability for current and future period cross the Benin country. Our future studies will focus on these limitations. 


\section{Data Availability}

The data used in this study are supplied by the local service of "Météo-Bénin" in Cotonou. The data are not available online in any database so that we cannot provide a link to reach them. They are provided when researchers address requests to "Météo-Bénin" (http://www.asecna.aero).

\section{Declaration of Conflicting Interests}

The authors declared no potential conflicts of interest with respect to the research, authorship, and/or publication of this article.

\section{References}

Admasu, W., Tadesse, K., Yemenu, F., \& Abdulkadir, B. (2014). Markov Chain Analysis of Dry, Wet Weeks and Statistical Analysis of Weekly Rainfall for Agricultural Planning at Dhera, Central Rift Valley Region of Ethiopia. African Journal of Agricultural Research, 9, 2205-2213. https://doi.org/10.5897/AJAR2014.8664

Afouda, A. (1988). Développement de l'hydrologiethéoriqueen Afrique de l'Ouest. In Actes du séminaire sur l'état de l'eauenhydrologie et enhydrogéologie dans les zones arides et semi-aridesd'Afrique (pp. 2-11). Pub. IWRA.

Afouda, A. (1989). A Consistent State Parameter for Hydrological Studies. In Proceedings of International Conference on FRIENDS in Hydrology (pp. 107-118). IAHS-Publ. No. 187.

Afouda, A. (1990). On the Stochastic Structure of Precipitation. In Proceeding Published by University of Padova, Italy (pp. 57-71).

Afouda, A., \& Adisso, P. (1997). Etude stochastique des structures de séquencessèches au Bénin. In Sustainability of Water Resources under Increasing Uncertainty (pp. 43-50). IAHS Publ. No. 240.

Afouda, A., Agbossou, K. E., \&Toukon, C. (2002). Caractérisation de la variabilité du régime pluviométriquebéninois et de son impact sur la production vivrière: Cas du maïs (Zea mays L.). In 5è Conférence Inter-Régionalesurl'Environnement et l'Eau. Envirowater 2002 (pp. 102-108).

Agbazo, M. N., Koto N’Gobi, G., Alamou, E., Kounouhewa, B., \& Afouda, A. (2019). Fractal Analysis of the Long-Term Memory in Precipitation over Benin (West Africa). Advances in Meteorology, 2, 1-12. https://doi.org/10.1155/2019/1353195

Agbazo, M. N., Koto N’Gobi, G., Alamou, E., Kounouhewa, B., \& Afouda, A. (2021). Assessing Nonlinear Dynamics and Trends in Precipitation by Ensemble Empirical Mode Decomposition (EEMD) and Fractal Approach in Benin Republic (West Africa). Complexity, 2021, Article ID: 3689397. https://doi.org/10.1155/2021/3689397

Anagnostopoulou, C., Maheras, P., Karacostas, T., \& Vafiadis, M. (2003). Spatial and Temporal Analysis of Dry Spells in Greece. Theoretical and Applied Climatology, 74, 77-91. https://doi.org/10.1007/s00704-002-0713-5

Barron, J., Rockström, J., Gichuki, F., \& Hatibu, N. (2003). Dry Spell Analysis and Maize Yields for Two Semi-Arid Locations in East Africa. Agricultural and Forest Meteorology, 117, 23-37. https://doi.org/10.1016/S0168-1923(03)00037-6

Bekele, E. (2001). Markov Chain Modeling and ENSO Influences on the Rainfall Seasons of Ethiopia. Natl. Meteorol. Agency Ethiop. http://www.wamis.org/agm/pubs/agm7/Bekele.pdf 
Biamah, E. K., Sterk, G., \& Sharma, T. C. (2005). Analysis of Agricultural Drought in Iiuni, Eastern Kenya: Application of a Markov Model. Hydrological Processes, 19, 1307-1322. https://doi.org/10.1002/hyp.5556

Boko, M. (1988). Climats et communautés rurales du Benin. Rythmes climatiques et rythmes de développement. Thèse de doctorat en Géographie, ABES.

Bonsal, B. R., \& Lawford, R. G. (1999). Teleconnections between El Nino and La Nina Events and Summer Extended Dry Spells on the Canadian Prairies. International Journal of Climatology, 19, 1445-1458.

https://doi.org/10.1002/(SICI)1097-0088(19991115)19:13<1445::AID-JOC431>3.0.CO; $2-7$

Cahill, A. T. (2003). Significance of AIC Differences for Precipitation Intensity Distributions. Advances in Water Resources, 26, 457-464. https://doi.org/10.1016/S0309-1708(02)00167-7

Chaudry, Q., Sheikh, M. et al. (2001). History's Worst Drought Conditions Prevailed over Pakistan.

Dayeen, F., \& Hassan, M. (2016). Multi-Multifractality, Dynamic Scaling and Neighbourhood Statistics in Weighted Planar Stochastic Lattice. Chaos, Solitons \& Fractals, 91, 228-234. https://doi.org/10.1016/j.chaos.2016.06.006

Douguedroit, A. (1987). The Variations of Dry Spells in Marseilles from 1865 to 1984. International Journal of Climatology, 7, 541-551. https://doi.org/10.1002/joc.3370070603

Epifani, C., Esposito, S., \& Vento, D. (2004). Persistence of Wet and Dry Spells in Italy. First Results in Milano from 1858 to 2000. In Proceedings from the 14th International Conference on Clouds and Precipitation 2004 (pp. 18-24). Bologna.

Ezeh, C. U., Obeta, M. C., \& Anyadike, R. N. C. (2016). Variations in the Sequences of Daily Rainfall across Nigeria. Arabian Journal of Geosciences, 9, 681.

https://doi.org/10.1007/s12517-016-2719-9

FAO (2016). Food and Agriculture-Key to Achieving the 2030 Agenda for Sustainable Development. Food and Agriculture Organization of the United States I5499: 32.

Feder, J. (1988). Fractals (284 p.). Springer. https://doi.org/10.1007/978-1-4899-2124-6

Feng, D.-J., Rao, H., \& Wang, Y. (2015). Self-Similar Sub-Sets of the Cantor Set. Advances in Mathematics, 281, 857-885. https://doi.org/10.1016/j.aim.2015.06.002

Fischer, B. M. C., Mul, M. L., \& Savenije, H. H. G. (2013). Determining Spatial Variability of Dry Spells: A Markov-Based Method, Applied to the Makanya Catchment, Tanzania. Hydrology and Earth System Sciences, 17, 2161-2170. https://doi.org/10.5194/hess-17-2161-2013

Froidurot, S., \& Diedhiou, A. (2017). Characteristics of Wet and Dry Spells in the West African Monsoon System. Atmospheric Science Letters, 18, 125-131. https://doi.org/10.1002/asl.734

Girma, B. A., Birtukan, A. H., Chul-Hee, L., \& Woo-Kyun, L. (2020). Spatial and Temporal Analysis of Dry and Wet Spells in Upper Awash River Basin, Ethiopia. Water, 12, 3051. https://doi.org/10.3390/w12113051

Goltz, C. (1997). Fractal and Chaotic Properties of Earthquakes. Lecture Notes in Earth Sciences Vol. 77. Springer. https://doi.org/10.1007/BFb0028315

Gong, D. Y., Wang, J. A., \& Han, H. (2005). Trends of Summer Dry Spells in China during the Late Twentieth Century. Meteorology and Atmospheric Physics, 88, 203-214. https://doi.org/10.1007/s00703-004-0081-z

Gornall, J., Betts, R., Burke, E., Clark, R., Camp, J., Willett, K., \& Wiltshire, A. (2010). 
Implications of Climate Change for Agricultural Productivity in the Early Twenty-First Century. Philosophical Transactions of the Royal Society of London. Series B: Biological Sciences, 365, 2973-2989. https://doi.org/10.1098/rstb.2010.0158

Groisman, P. Y., \& Knight, R. W. (2008). Prolonged Dry Episodes over the Conterminous United States: New Tendencies Emerging during the Last 40 Years. Journal of Climate, 21, 1850-1862. https://doi.org/10.1098/rstb.2010.0158

Harrington, J., \& Flannignan, M. (1993). A Model for the Frequency of Long Periods of Drought at Forested Stations in Canada. Journal of Applied Meteorology, 32, 1708-1716. https://doi.org/10.1175/1520-0450(1993)032<1708:AMFTFO>2.0.CO;2

Hayhoe, H. N. (2000). Improvements of Stochastic Weather Data Generators for Diverse Climates. Climate Research, 14, 75-87. https://doi.org/10.3354/cr014075

Hubert, P., Tessier, Y., Lovejoy, S., Shertzer, D., Schmitt, F., Ladoy, P., Carbonnel, J. P., Violette, S., \& Desurosne, I. (1993). Multifractal and Extreme Rainfall Events. Geophysical Research Letters, 20, 931-934. https://doi.org/10.1029/93GL01245

Hui, W., Xuebin, Z., \& Elaine, M. B. (2005). Stochastic Modelling of Daily Precipitation for Canada. Atmosphere-Ocean, 43, 23-32. https://doi.org/10.3137/ao.430102

Hurst, H. E. (1951). Long-Term Storage of Reservoirs: An Experimental Study. Transactions of the American Society of Civil Engineers, 116, 770-799. https://doi.org/10.1061/TACEAT.0006518

Huth, R., Kyselyy, J., \& Pokorna, L. (2000). A GCM Simulation of Heat Waves, Dry Spells, and Their Relationships to Circulation. Climatic Changes, 46, 29-60. https://doi.org/10.1023/A:1005633925903

Jayawardene, H. K. W. I., Sonnadara, D. U. J., \& Jayewardene, D. R. (2005). Trends in Rainfall in Sri Lanka over the Last Century. Sri Lankan Journal of Physics, 6, 7-17. https://doi.org/10.4038/sljp.v6i0.197

Kendziorski, C. M. (1999). Evaluation Maximum Likelihood Estimation Methods to Determine the Hurst Coefficient. Physica A, 273, 439-451. https://doi.org/10.1016/S0378-4371(99)00268-X

Kutiel, H., \& Maheras, P. (1992). Variations interannuelles des séquences sèches et des situations synoptiques en Méditerranée. Publications de l'AIC, 5, 15-27.

Lana, X., Burgueño, A., Serra, C., \& Martínez, M. D. (2015). Multifractality and Autoregressive Processes of Dry Spell Lengths in Europe: An Approach to Their Complexity and Predictability. Theoretical and Applied Climatology, 127, 285-303.

https://doi.org/10.1007/s00704-015-1638-0

Lana, X., Martinez, M. D., Burgueno, A., Serra, C., Martın-Vide, J., \& Gomez, L. (2006). Distribution of Long Dry Spells in the Iberian Peninsula, Years 1951-1990. International Journal of Climatology, 26, 1999-2021. https://doi.org/10.1002/joc.1354

Lana, X., Martínez, M. D., Burgueño, A., \& Serra, C. (2008b). Return Period Maps of Dry Spells for Catalonia (North-Eastern Spain) Based on the Weibull Distribution. Hydrological Sciences Journal, 53, 48-64. https://doi.org/10.1623/hysj.53.1.48

Lana, X., Martínez, M. D., Burgueño, A., Serra, C., Martín-Vide, J., \& Gomez, L. (2008a). Spatial and Temporal Patterns of Dry Spell Lengths in the Iberian Peninsula for the Second Half of the Twentieth Century. Theoretical and Applied Climatology, 91, 99-116. https://doi.org/10.1007/s00704-007-0300-X

Lana, X., Martínez, M. D., Serra, C., \& Burgueño, A. (2010). Complex Behaviour and Predictability of the European Dry Spell Regimes. Nonlinear Processes in Geophysics, 17, 499-512. https://doi.org/10.5194/npg-17-499-2010

Lázaro, R., Rodrigo, F. S., Gutirrez, L., Domingo, F., \& Puigdefáfragas, J. (2001). Analysis 
of 30-Year Rainfall Record in Semi-Arid SE Spain for Implications on Vegetation. Journal of Arid Environments, 48, 373-395. https://doi.org/10.1006/jare.2000.0755

Le Barbé, L., \& Lebel, T. (1997). Rainfall Climatology of HAPEX-Sahel Region during the Years 1950-1990. Journal of Hydrology, 188-189, 43-73. https://doi.org/10.1016/S0022-1694(96)03154-X

Lovejoy, S., \& Mandelbrot, B. B. (1985). Fractal Properties of Rain and a Fractal Model. Tellus A, 37, 209-232. https://doi.org/10.1111/j.1600-0870.1985.tb00423.x

Lucena, L. R. R. D., Júnior, S. F. A. X., Stosic, T., \& Stosic, B. (2018). Lacunarity Analysis of Daily Rainfall Data in Pernambuco, Brazil. Acta Scientiarum Technology, 40, e36655. https://doi.org/10.4025/actascitechnol.v40i1.36655

Mandelbrot, B. (1985). Self-Affinity and Fractal Dimension. Physica Scripta, 32, 257-260. https://doi.org/10.1088/0031-8949/32/4/001

Manikandan, M., Thiyagarajan, G., Bhuvaneswari, J., \& Prabhakaran, N. K. (2017). Wet and Dry Spell Analysis for Agricultural Crop Planning Using Markov Chain Probability Model at Bhavanisagar. International Journal of Mathematics and Computer Applications Research, 7, 11-22.

Martınez, M. D., Lana, X., Burgueno, A., \& Serra, C. (2007). Lacunarity, Predictability and Predictive Instability of the Daily Pluviometric Regime in the Iberian Peninsula. Nonlinear Processes in Geophysics, 14, 109-121. https://doi.org/10.5194/npg-14-109-2007

Matarira, C. H., \& Jury, M. R. (1992). Contrasting Meteorological Structure of Intra-Seasonal Wet and Dry Spells in Zimbabwe. International Journal of Climatology, 12, 165-176. https://doi.org/10.1002/joc.3370120205

Mathugama, S. C., Peiris, T. S. G. (2011). Critical Evaluation of Dry Spell Research. International Journal of Basic and Applied Sciences, 6, 153-160.

Mittall, A., \& Bhardwaj, R. (2011). Predictability Index, Fractal Dimension, and Hurst Exponent Estimation of Indian Air Pollution Parameters. International Journal of Advanced Science and Research, 2, 363-374.

Monjo, R. (2016). Measure of Rainfall Time Structure Using the Dimensionless n-Index. Climate Research, 67, 71-86. https://doi.org/10.3354/cr01359

Monjo, R., Royé, D., \& Martin-Vide, J. (2019). Drought Lacunarity around the World and Its Classification (Version v0.1) [Data Set], Zenodo. https://doi.org/10.5194/essd-2019-115

Muller, A. (2006). Comportementasymptotique de la distribution des pluiesextrêmesen France. Thèse de l'Université de Montpellier II, Sciences et Techniques de Languedoc.

Peng, C., Buldyrev, S., Havlin, S., Simons, M., Stanley, H., \& Goldberger, A. (1994). Mosaic Organization of DNA Nucleotides. Physical Review E, 49, 1685-1689. https://doi.org/10.1103/PhysRevE.49.1685

Perzyna, G. (1994). Spatial and Temporal Characteristics of Maximum Dry Spells in Southern Norway. International Journal of Climatology, 14, 895-909. https://doi.org/10.1002/joc.3370140806

Peters, E. E. (1994). Fractal Market Analysis: Applying Chaos Theory to Investment and Economic. John Wiley and Sons.

Rangarajan, G., \& Sant, D. A. (1997). A Climate Predictability Index and Its Applications. Geophysical Research Letters, 24, 1239-1242. https://doi.org/10.1029/97GL01058

Rangarajan, G., \& Sant, D. A. (2004). A Fractal Dimensional Analysis of Indian Climatic Dynamics. Chaos, Solitons and Fractals, 19, 285-291.

https://doi.org/10.1016/S0960-0779(03)00042-0 
Reddy, G. S., Bhaskar, S., Purohit, R., \& Chittora, A. (2008). Markov Chain Model Probability of Dry, Wet Weeks and Statistical Analysis of Weekly Rainfall for Agricultural Planning at Bangalore. Karnataka Journal of Agricultural Sciences, 21, 12-16.

Rockstrom, J. (2000). Water Resources Management in Smallholder Farms in Eastern and Southern Africa: An Overview. Physics and Chemistry of the Earth, Part B: Hydrology, Oceans and Atmosphere, 25, 275-283. https://doi.org/10.1016/S1464-1909(00)00015-0

Salack, S., Klein, C., Giannini, A., Sarr, B., Worou, O. N., Belko, N., Bliefernicht, J., \& Kunstman, H. (2016). Global Warming Induced Hybrid Rainy Seasons in the Sahel. Environmental Research Letters, 11, Article ID: 104008. https://doi.org/10.1088/1748-9326/11/10/104008

Sanogo, S., Fink, A. H., Omotosho, J. A., Ba, A., Redl, R., \& Ermert, V. (2015). SpatioTemporal Characteristics of the Recent Rainfall Recovery in West Africa. International Journal of Climatology: A Journal of the Royal Meteorological Society, 35, 4589-4605. https://doi.org/10.1002/joc.4309

Seleshi, Y., \& Camberlin, P. (2006). Recent Changes in Dry Spell and Extreme Rainfall Events in Ethiopia. Theoretical and Applied Climatology, 83, 181-191. https://doi.org/10.1007/s00704-005-0134-3

Serra, C., Burgueno, A., Martınez, M. D., \& Lana, X. (2006). Trends of Dry Spells across Catalonia (NE Spain) for the Second Half of the 20th Century. Theoretical and Applied Climatology, 85, 165-183. https://doi.org/10.1007/s00704-005-0184-6

Serra, C., Martínez, D., Lana, X., \& Burgueño, A. (2013). Europeandry Spell Length Distributions, Years 1951-2000. Theoretical and Applied Climatology, 114, 531-551. https://doi.org/10.1007/s00704-013-0857-5

Serra, C., Martínez, M. D., Lana, X., \& Burgueño, A. (2014). European Dry Spell Regimes (1951-2000): Clustering Process and Time Trends. Atmospheric Research, 144, 151-174. https://doi.org/10.1016/j.atmosres.2013.05.022

Sharma, T. C. (1996). Simulation of the Kenyan Longest Dry and Wet Spells and the Largest Rain-Sums Using a Markov Model. Journal of Hydrology, 178, 55-67. https://doi.org/10.1016/0022-1694(95)02827-7

Sirangelo, B., Caloiero, T., Coscarelli, R., \& Ferrari, E. (2019). A Stochastic Approach for the Analysis of Long Dry Spells with Different Threshold Values in Southern Italy. Water, 11, 26. https://doi.org/10.3390/w11102026

Sivakumar, B., Sorooshian, S., Gupta, H. V., \& Gao, X. (2001). A Chaotical Approach to Rainfall Disaggregation. Water Resources Research, 37, 61-72. https://doi.org/10.1029/2000WR900196

Sivakumar, M. (1992). Empirical Analysis of Dry Spells for Agricultural Applications in West Africa. Journal of Climate, 5, 532-539. https://doi.org/10.1175/1520-0442(1992)005<0532:EAODSF>2.0.CO;2

Taqqu, M. S., Teverovsky, V., \& Willinger, W. (1995). Estimators for Long Range Dependence: An Empirical Study. Fractals, 3, 785-788. https://doi.org/10.1142/S0218348X95000692

Tatli, H. (2015). Detecting Persistence of Meteorological Drought via Hurst Exponent. Meteorological Applications, 22, 763-769. https://doi.org/10.1002/met.1519

Voss, R. F. (1985). Random Fractals: Characterization and the Measurement. In R. Pynn, \& A. Skjeltorp (Eds.), Scaling Phenomena in Disordered Systems (27-32). Plenum.

Whitworth, K. L., Baldwin, D. S., \& Kerr, J. L. (2012). Drought, Floods and Water Quality: Drivers of a severe Hypoxic Blackwater Event in a Major River System (the Southern Murray-Darling Basin, Australia). Journal of Hydrology, 450-451, 190-198. 
https://doi.org/10.1016/j.jhydrol.2012.04.057

Wilks, D. S. (1999). Interannual Variability and Extreme-Value Characteristics of Several Stochastic Daily Precipitation Modes. Agricultural Meteorology, 93, 153-169. https://doi.org/10.1016/S0168-1923(98)00125-7

Wilks, D. S. (2006). Statistical Methods in the Atmospheric Sciences (p. 627, 2nd ed.). International Geophysics Series, Vol. 59, Elsevier Academic Press.

Zolina, O., Simmer, C., Belyaev, K., Gulev, S. K., \& Koltermann, P. (2013). Changes in the Duration of European Wet and Dry Spells during the Last 60 Years. Journal of Climate, 26, 2022-2047. https://doi.org/10.1175/JCLI-D-11-00498.1 